\title{
Guenoa minuanos: caciques y territorio
}

\section{Guenoa minuanos: chieftains and territory}

\author{
Guenoa minuanos: caciques e território
}

Diego Bracco*

José María Lopez Mazz*

\begin{abstract}
Resumen: Este artículo está centrado en el análisis del rol desempeñado por los caciques de la nación que los jesuitas denominaron guenoa y el resto de la sociedad colonial minuan. Parte relevante del trabajo está centrado en el sistema jerárquico -con la existencia de un jefe máximoque tuvieron durante dilatado lapso. Asimismo en la superioridad que al parecer mantuvieron sobre sus propios dirigentes religiosos. También se analizan fuentes que permiten aproximarse a los requisitos o circunstancias necesarias para obtener el rango de cacique. Igualmente, las referidas a la poligamia que practicaron; así también las relacionadas con el ganado que tuvieron en régimen de propiedad privada. Por último, se formulan consideraciones sobre el dilatado espacio en el que ejercieron su dominio y sus relaciones con aquel donde está emplazada gran cantidad de los denominados "cerritos de indios".
\end{abstract}

Palabras clave: Guenoa minuanos. Caciques. Territorio

\begin{abstract}
This article focuses on the analysis of the role played by the chiefs of the nation that the Jesuits called Guenoa and the rest of the colonial society mined. Relevant part of the work is centered on the hierarchical system - with the existence of a maximum leader - that they had during a long period. Also in the superiority that apparently maintained over their own religious leaders. Sources that allow to approximate the requirements or circumstances necessary to obtain the rank of chief are also analyzed. Likewise, those referring to the polygamy they practiced; as well as those related to cattle that they had under private property. Finally, considerations are made about the extensive space in which they exercised their domain and their relations with that where a large number of the so-called "Indian pigs" are located.
\end{abstract}

Keywords: Guenoa minuanos. Chieftains. Territory

Resumo: Este artigo enfoca a análise do papel desempenhado pelos chefes da nação que os jesuítas chamavam de Guenoa e o restante da sociedade colonial. Parte relevante do trabalho está centrada no sistema hierárquico - com a existência de um líder máximo - que eles tiveram durante um longo período. Também na superioridade que aparentemente mantinham sobre seus próprios líderes religiosos. Também são analisadas fontes que permitem aproximar os requisitos ou circunstâncias necessárias para obter o posto de chefe. Da mesma forma, aqueles que se referem à poligamia que praticaram; bem como aqueles relacionados ao gado que possuíam sob propriedade privada. Finalmente, considerações são feitas sobre o amplo espaço em que 
exerceram seu domínio e suas relações com aquele onde se localiza um grande número dos chamados "porcos indianos".

Palavras-chave: Guenoa minuanos. Caciques. Território.

\section{Introducción}

La nación que los jesuitas llamaron guenoa y el resto de la sociedad colonial minuana adquirió gran visibilidad en las fuentes a partir de la década de 1680. Sin perjuicio de que la documentación a ella referida es relativamente abundante en el siglo y medio subsiguiente, son numerosos los aspectos poco conocidos de su organización social. Entre ellos destaca el de las relaciones de poder al interior de los guenoa minuanos. Esta contribución busca analizar esas relaciones especialmente en lo atinente al rol que desempeñaban los caciques. Para ello pretende acercarse a la comprensión de variables relacionadas con jerarquía, herencia, género y territorio entre otras. En algunos casos se emplean ejemplos útiles para el análisis comparativo, referidos a "naciones" "infieles" que actuaron en similar tiempo y/o territorio.

El principal sesgo de la documentación disponible está relacionado con la introducción de categorías propias del observador. Ello es muy notable en las referencias al carácter hereditario del cacicazgo o a la existencia de "cacicas". Tal, en parte, es debido a que esos dirigentes tendieron a ser funcionales a los intereses de la administración colonial española (WEBER, 2007, p. 21). Cacique era definido en la primera mitad del siglo XVIII como "señor de vasallos, o el superior en la provincia o pueblo de los indios: y aunque en muchas partes de las Indias tienen otros nombres, según sus idiomas, los españoles los llaman a todos caciques, que parece lo tomaron de las Islas de Barlovento, que fueron las primeras que se conquistaron. Es voz mejicana, que significa señor'(REAL ACADEMIA ESPAÑOLA, 1729). En la misma entrada del diccionario se recordaba que: "Recop de Ind. lib. 6, tit. 7 f 12: ningún juez ordinario pueda prender cacique ni principal, si no fuere por delito grave" (REAL ACADEMIA ESPAÑOLA, 1729).

\section{Cacique, “Quireimbá”, “Karaí” o Rey}

De acuerdo a Aurelio Porto (1954, p. 70) entre los guenoa minuanos algunos "pela descendência ou mútuo acordo, eram os caciques dos bandos que obedeciam a um cacique geral, ou rei”. Las fuentes respaldan esa afirmación, evidenciando que durante prolongado lapso hubo un sistema jerárquico entre dirigentes de las distintas parcialidades. Sin embargo no explicitan 
con claridad los mecanismos que conferían el rango de cacique o de, al decir del autor antes mencionado, "Rey".

Al igual que los de otras naciones, los guenoa minuanos se convocaban "unos caciques a otros, aunque vivan muy lejos, con los humos, o resplandores de las grandes hogueras, que encienden cada uno en su territorio, para avisar que hay enemigos en sus tierras, y que es necesario unirse muchos a la defensa" (JARQUE, 1687, p. 372). Cuando en el año 1683 estuvo entre ellos el padre Francisco García (1683 apud JARQUE, 1687, p. 374 - 382) quizás se diera esa circunstancia ya que "los yarós, otros bárbaros, sus enemigos [habían, hacia oriente] (...) pasado el rio Uruguay (1687, p. 374 - 382). Tal podría explicar por qué el mencionado religioso se encontró con un conjunto de caciques. Entre ellos había principales y -obvio- secundarios. Conviene señalar que según el referido jesuita en determinado momento "se juntaron algunos de los caciques, y continuando mis doctrinas, dijo uno, sobrino del mas principal...” (1687, p. 374 - 382). De tal afirmación se desprende que había un cacique con autoridad sobre todos los demás. De ese hombre se dijo que "era mayor de todos" (1687, p. 374 - 382) aunque es difícil establecer si la expresión fue empleada como sinónimo de autoridad o edad. Tal duda parece quedar resuelta porque más adelante García lo llamó “más principal” y no mayor (1687, p. 374 - 382). Ese "más principal" tenía la potestad de autorizar la partida de "una hermana, con su marido, y tres o cuatro hijos, que deseaba venir, porque ya tenían aquí [en Santo Tomé] otras dos hijas" (1687, p. 374 - 382). Como se ha visto ese hombre era tío de un joven, también cacique, sin que sea posible establecer si por razones hereditarias. En cualquier caso había entre los guenoa minuanos que visitó García en el año 1683 dos jefes principales: el "tío" "y otro cacique llamado Yaguareté, a quienes seguían todos los demás, por ser estos dos los más principales, que los supeditan" (1687, p. 374 - 382).

También había caciques principales y secundarios entre los guenoa minuanos que se habían reunido en el año 1688 con el aparente propósito de recibir o acompañar al padre Alonso del Castillo, procedente de Yapeyú. Esos “infieles” estaban cerca de la costa atlántica en lo que parece un lugar del actual departamento de Rocha, Uruguay. Allí fueron sorprendidos por portugueses que buscaban esclavizarlos y que, en un primer ataque "les mataron a los dos caciques más principales que tenían, con otros dos mozos [e hirieron] a otro valentón de ellos, Bernabé el apóstata".ii

Similares aspectos de la organización de la nación guenoa minuana pueden verse en fuentes producidas durante el proceso fundacional de Montevideo. Por entonces el franciscano Jerónimo de la Cruz tuvo varias "consultas con los más principales caciques minuanes". iii Las buenas relaciones iniciales devinieron hostilidad y los indígenas combatieron con éxito a las 
tropas enviadas desde la recién fundada Ciudad, aunque perdiendo "sus dos caciques principales". iv En aquel conflicto los jesuitas desempeñaron un rol fundamental como mediadores, convenciendo a numerosos jefes guenoa minuanos de las bondades de la paz. Esos se manifestaron bien dispuestos, condicionando su respuesta a que "si el Quireymba admitía las paces, todos ellos también la admitían". "Tal denominación, probablemente guaraní, se aplicaba a un jefe llamado Yaplemán al que se reconocía poder sobre toda la nación guenoa minuana. ${ }^{\mathrm{vi}}$ Así por ejemplo también tenía autoridad sobre dos caciques de "menor poder" establecidos "hacia la estancia del pueblo de San Miguel, los cuales ha tres o cuatro años, que viven allí sin cometer hostilidad contra español alguno; pero no obstante dice Quireymbá que les hará avisar de la paz". vii

La paz celebrada en el año 1732 entre Montevideo y los guenoa minuanos fue efímera. Durante la década de 1740 hubo intentos de establecer reducciones a cargo de jesuitas en el territorio de la actual República Oriental del Uruguay pero no tuvieron continuidad (LÓPEZ MAZZ; BRACCO, 2010). A principios de la década de 1750 hubo un ciclo hostil contra los charrúas (BRACCO, 2016). Igual aconteció con guenoa minuanos, cuyos caciques "infieles" murieron, fueron hechos prisioneros (al menos en un caso) o se refugiaron en los pueblos de misiones (BRACCO, 2013, p. 63 - 96).

Tras -y como consecuencia de- la denominada guerra guaranítica la interacción de parte de los guenoa minuanos con los pueblos de misiones tendió a empeorar. Debido a ello algunos caciques llegaron a Montevideo "en nombre de todos los otros caciques como que traían de ellos la facultad y que estos no pudieron bajar por quedarse estos en guarda en sus toldos". viii Y preguntados "cuál era el cacique principal de los indios que estaban en estas inmediaciones, respondieron los presentes que todos conocían por cacique de ellos al referido indio Cumandat (...) diciendo los dichos indios nuevamente venidos ahora que son cuatro caciques ya referidos, que el cacique Comiray, que es el mayor de dichos cuatro, y bajo de cuyas órdenes están, este se halla fuera, con su toldería agregada a la de don Christobal, y que hubiera venido también en esta ocasión con ellos a esta ciudad, de no haber sucedido el no tener caballo en que venir, por hallarse totalmente a pie". ix

Pareciera entonces que existían hasta cuatro niveles en la organización jerárquica de los caciques. En el lugar principal estaría uno, que no se nombra, que tendría el rol que en 1730 desempeñaba el Queyrembá Yapleman, con ascendencia sobre toda la nación. En el segundo lugar estaría el "cacique principal de los indios que estaban en estas inmediaciones (...) Cumandat". ${ }^{x}$ En tercer sitio estaría Comiray, a quién obedecían los cuatro que habían ido a Montevideo. Y, en cuarto lugar jerárquico los que habían ido a Montevideo, don Christobal y 
un número no susceptible de ser cuantificado.

Resulta de un gran interés advertir que Comiray carecía de caballada y había precisado agregarse a la toldería de don Christobal. Ello demostraría que el poder - caballos y quizás hombres de armas- no eran determinantes para el orden jerárquico entre los caciques.

Dos décadas más tarde fue señalado que "ha entre elles huns, que ou pela sua descendencia, ou mutuo acordo os dominâo" (SALDANHA, 1938 apud ACOSTA Y LARA, 1998, p. 248 - 251) ejercían el mando. Por entonces Salteinho, Maulein, Batú, Tajuy y Don Miguel eran caciques. Tajuy era "alto, bem proporcionado, e dezembaraçado. O Salteinho hé ja velho (...) O Batú he alto, velho, carancudo, e feyo. O D. Miguel he mais baixo, gordo e mosso e de semblante alegre, e mais racionavel"(1998, p. 248-251). ${ }^{\mathrm{xi}}$

Entre ellos era "rei D. Miguel Caraí, que foi o último dos minuanos e o primeiro gaúcho do campo" (PORTO, 1954, p. 70). Como se ha visto Saldanha destacó que era "mais baixo, gordo e mosso", evidenciando que la edad no era requisito para ser cacique de caciques. Es posible conjeturar que Caraí -por el significado en guaraní de Karaí- guarde similitudes con el rango de Quireymbá que ostentaba Yapleman.

Como se ha visto las fuentes sugieren que Yaplemán tenía gran autoridad sobre todos los caciques de la nación guenoa minuana y lo mismo ocurría al parecer con Miguel Caraí. Hasta cierto punto en contradicción con ello el demarcador Alvear (1900) expresó “que esta subordinación de los caciques se limita a solo los casos en que se trata de la común defensa, o de vengar algún agravio general, y a este fin se juntan con gran facilidad, pasando la noticia de alarma de unos toldos a otros en breves instantes por medio de los fuegos o humos". xii

Hacia el final del denominado período colonial los caciques minuanos continuaron siendo actores principales en la Región. Algunos tendieron a unir su suerte a la de los charrúas, como Zará, que murió luchando junto a ellos en el combate del Corral de Sopas de primero de mayo de 1801 (BRACCO, 2014, p. 137). Otros encabezaban grupos numerosos; por ejemplo Masalana dispondría en esa misma época de unos 80 guerreros. ${ }^{\text {xiii }}$ En cualquier caso a partir de la crisis del sistema colonial las fuentes no permiten visualizar a la nación guenoa minuana como conjunto. No obstante, para referir a un solo ejemplo, el acuerdo de paz alcanzado entre Lecor y dos caciques guenoa minuanos con la mediación de Manduré sugiere que tenían gran poder. ${ }^{\text {xiv }}$ Para entonces -y desde mucho antes- se desarrollaban procesos -por ejemplo los de sustitución de apellidos- que añaden dificultades para conocer trayectoria y alcance del poder de los caciques. Asimismo operaron en ese sentido los procesos de asimilación y / o integración a la sociedad colonial que desdibujaron la procedencia étnica. En ese contexto resulta del mayor interés la posibilidad de que, contra lo generalmente aceptado, los principales dirigentes 
indígenas que adhirieron a la denominada "Revolución Artiguista" hayan sido guenoa minuanos. Sarmiento (1883, p. 162) afirmó de los hombres de Artigas que: "de la misma catadura; son los charrúas, los guaraníes, los minuanos. Andresito es indio minuano". Parecida afirmación realizó Frías (2018 III 515) a principios de siglo XX: "Llamábase, por ejemplo, Andresito, uno de ellos, quizá el principal, y era un indio minuano, que ni su padre sabía quién hubiera sido, cargando el apellido de Artigas”. $\quad$ También, según Sarmiento (1883, p. 162) "los jefes de esta división eran indios minuanos. El indio Ticurey, el indio Lorenzo Artigas, por adopción como Andresito, el indio Matías Abacú, el indio Juan de Dios, etc.”. Asimismo es preciso agregar, aunque ello no autoriza a considerarlo de esa nación, que el relevante dirigente Manduré era "pariente" y hablaba la lengua de los guenoa minuanos. ${ }^{\mathrm{xv}}$ Por supuesto las afirmaciones precedentes no pueden aceptarse sin más pero abren una muy interesante interrogante acerca de la continuidad de los liderazgos guenoa minuanes.

\section{Un cacique "menor"}

Como se ha visto, en 1683 un cacique "menor" sobrino del "más principal" siguió al padre García en su regreso a Santo Tomé. Era propietario de "cantidad" de vacas y caballos que debió abandonar para que su partida pasara inadvertida (GARCÍA, 1683 apud JARQUE, 1687, p. 374 - 382). Habría sido especialmente valeroso y, en circunstancias no descritas, fue dejado solo frente al enemigo. Muchos, entre ellos dos caciques y un "hechicero", lo acompañaron 4 leguas procurando convencerlo de que no emigrara; en ese mismo intento algunos marcharon a su lado hasta 10 leguas.

El cacique "menor" emigró con 15 personas: "tres mujeres suyas, y su madre, un cuñado, hijos, y sobrinos, excelentes mozos". Cabe conjeturar que los sobrinos eran hijos de su cuñado; por razones no explicitadas - quizás fallecimiento - la madre de esos niños no formaba parte del grupo. En cualquier caso no parece que los 15 que acompañaban al "cacique sobrino" fueran la totalidad de sus "parciales". Tampoco lo eran de su familia ya que "a diez y siete de noviembre [de 1683, a Santo Tomé] llegaron doce infieles, con vacas para vender a este Pueblo, entre ellos venia un hijo del cacique fervoroso, que yo traje, y venia con intento de inquirir, que vida era la de los cristianos, que comodidades, \&c. y volver a informar a otros, que lo deseaban saber. Se quedó de esta vez con su padre, y llevó otro el informe (GARCÍA, 1683 apud JARQUE, 1687, p. 374 - 382)".

La carta del padre García induce a creer que entre los guenoa minuanos había elevado grado de aquello que con nuestros parámetros denominaríamos libertad. Así lo sugieren los 
intensos intentos de persuadir pero no de impedir la emigración del cacique "menor". Como se verá más adelante tal libertad habría alcanzado a la relación entre caciques y "vasallos", así como en algunos aspectos a las mujeres.

A partir de las circunstancias del cacique "menor" es posible formular algunas cuestiones acerca de los requisitos que conferían ese rango. No es posible determinar cuánto si algo- influía en su propia condición que fuera sobrino del "más principal”. El hijo que lo visitó cuando ya estaba en Santo Thomé no fue señalado como cacique pero, por ejemplo, podría no ser el primogénito. En ese sentido, lo hereditario parece jugar algún rol. Cabe recordar que también junto al padre García había marchado "otro cacique muchacho (...) menos constante, retrocedió, volviéndose con los gentiles a su madre viuda, que no había querido acompañarle” (GARCÍA, 1683 apud JARQUE, 1687, p. 374 - 382). Entonces “muchacho" “en su riguroso sentido vale el niño que mama; aunque comunmente se extiende a significar el que no ha llegado a la edad adulta (REAL ACADEMIA ESPAÑOLA, 1736, p. 621 - 622)”. Aunque no es posible determinar qué reglas de parentesco -si alguna- aplicaban, parece obvio que un niño no pudo ser elegido por sus dotes de mando.

Antes se ha señalado que quien hemos denominado cacique "menor" habría demostrado importante valor. Es posible que tal virtud fuera indispensable para mantener la condición de cacique en aquel medio, pero no suficiente para otorgarla. Así, el "valentón” Bernabé el apóstata, protagonista a la hora de repeler el ataque portugués que pretendía esclavizarlos en 1688 no parece cacique. ${ }^{\mathrm{xvi}}$

Hacia fin de la década de 1720 un cacique llamado Coraya estuvo envuelto en una reyerta en la que acabó con la vida de un cacique rival. Cuando el padre Jiménez fue a tierras de los guenoa minuanos para mediar en el conflicto con Montevideo encontró entre otros a "un hijo de Coraya, el fautor de los christianos que avia yà muerto y este le avia sucedido en èl Cazigasgo" (CARTA ANUA DE 1730 - 1734 EN MANUSCRITOS DA COLEÇÂO DE ANGELIS, 1955, p. 165)". Así, el ejemplo precedente apunta hacia factores hereditarios; en cambio el de Miguel Karaí (mestizo; sólo su madre era guenoa minuana y con experiencia de vida en la sociedad colonial) parece señalar que la aptitud era determinante.

\section{Disenso entre caciques / disenso entre indios y caciques}

La nación guenoa minuana parece haber actuado en general como un todo (LÓPEZ MAZZ; BRACCO, 2010). Pareciera que al interior de esa nación se actuaba con elevado grado de aquello que de acuerdo a nuestros parámetros denominaríamos libertad. Por supuesto ello no 
significa la ausencia de disensiones entre "vasallos" y caciques, o aún entre estos. Por ejemplo al principio de la guerra que sacudió la Región en 1701 - 1702 sólo una parte se sumó a la coalición “infiel” que amenazaba los pueblos de misiones (BRACCO, 2004, p. 197 - 252). Dos décadas más tarde el gobernador de Colonia del Sacramento se quejaba de que los guenoa minuanos estaban muy enojados debido a las diferencias que hacía entre los caciques porque todos querían ser iguales, sin reconocer superioridad a ninguno. ${ }^{\mathrm{xvii}} \mathrm{Y}$ en el escenario de la guerra contra la recién fundada Montevideo el padre Jerónimo Herrán hizo gestiones ante "los caciques que no queriendo participar en la guerra, se habían arrimado a Misiones". ${ }^{\text {xiii }}$ Sin que sea posible determinar si debido a ese u otro motivo, por entonces hubo "una pendencia, en la cual un cacique llamado Coraya, indio que siempre ha favorecido a los cristianos de la reducción del Yapeyú, quitó la vida a otro cacique de la parcialidad contraria. Esta muerte alborotó toda la nación y puso en armas unas parcialidades contra otras". xix

No obstante parecen excepcionales los casos que pusieron a los guenoa minuanos en situación equiparable a la guerra civil. Hacia el final del denominado período colonial la negociación del cacique guenoa minuan Masalana con los enviados del virrey Avilés ilustra con vivos colores aspectos de la relación entre un cacique y sus "vasallos". Ante ellos: "se presentó el cacique Masalana con 38 infieles armados a quien y a quienes recibí con aprecio (...) Le expresé (...) se redujera a población para recibir las aguas del bautismo (...) pues por medio de estas, llegaría a gozar, después de esta vida, de la gloria. A cuyo razonamiento uno de los infieles, parlando en su idioma, diciendo que no era verdad (...) ni menos eran criados para la gloria, pues el alma de ellos era como la de un animal que muerto quedaba en la nada (...)Y a esto me contestó el cacique Masalana, que hasta aquí no me había contestado, que él, de su parte, no dudaba seguir el dictamen del señor virrey pero que sus vasallos eran opuestos pues [me dijo] que observe con el disgusto que escuchaban las órdenes de Su Excelencia en su domicilio". ${ }^{\mathrm{xx}}$

\section{Caciques, guerreros y toldos}

Es difícil cuantificar la nación guenoa minuana incluso durante los períodos para los que existe relativa abundancia de fuentes. Parte considerable del problema deriva de que la sociedad colonial tendió a relacionarse con ellos -y a describirlos- desde los bordes del gran espacio en que fueron preponderantes (BRACCO, 2004). Asimismo a que recién en nuestro presente los estudiosos empiezan a cuantificar los que vivían de manera permanente en los pueblos de misiones (JACKSON, 2019, p. 67 - 68, 97, 150 - 151, 265, 267). También a que casi no disponemos al presente de cifras de los que habitaron entre españoles o portugueses (LÓPEZ 
MAZZ; BRACCO, 2010). Sin que haya fuentes similares para contrastar, en 1718 se sostuvo que esa nación constaba de más de 5.000 individuos y que un sólo cacique mandaba sobre 1.200 de ellos. ${ }^{x x i}$

Al parecer la célula básica en la organización social era la "estera" que, andando el tiempo, pasó a ser el "toldo". Tan pocos son los datos que para aportar indicios cuantitativos es preciso recurrir también a ejemplos de otros “infieles” de la región. Así, en 1701 tres mil "infieles" charrúas o al menos coaligados con ellos acampaban en 280 toldos, en un espacio de dos leguas. ${ }^{x i i}$ La apreciación que antecede indica, con las reservas derivadas de que la observación fue realizada en tiempos de guerra y a la distancia, unas 11 personas por toldo.

En 1703, bohanes sobrevivientes a la guerra de los dos años precedentes acampaban en 10 toldos. Allí había "ochenta indios de catorce años para arriba y diez y ocho indias grandes y dos pequeñitas". xxiii Por población mermada, desproporción de género y desconocimiento de los mecanismos de adaptación ante la crisis, la referencia debe tomarse con especial reserva; no obstante, indica unas 10 personas por toldo. En la década de 1730, durante los movimientos que precedieron a la fundación de Rio Grande, Silva Paes obsequió a un cacique guenoa minuan de quien le habían dicho que gobernaba 30 toldos. ${ }^{\text {xxiv }}$ A mediados de siglo XVIII y también en contexto hostil a unos 150 kilómetros al noreste de Montevideo había 32 toldos ocupados por unos 150 hombres de armas y unos 200 de "chusma" (REVISTA DEL ARCHIVO GENERAL ADMINISTRATIVO, 1885 - 1943. T. II, p. 225). Por el contexto y la desproporción de género la referencia debe ser tomada con cautela, ${ }^{\mathrm{xxv}}$ pero también parece indicar $10 \mathrm{u} 11$ personas por toldo. También es llamativo el desequilibrio de género, lo que induce a creer que en circunstancias normales los toldos tendrían algunas personas más. En la década de 1780 se indicó que "sobre los márgenes de estos arroyos [Ybirapitá miní y guazú, Ituzayngó, Caziquey, Toropoy] habitaban seis u ocho tolderías de indios minuanes, resto de la antigua nación de este nombre (...) cada una de dichas tolderías se compone como de 50 personas de uno y otro sexo, las cuales obedecen y se dirigen por las órdenes de un indio principal que llaman cacique". xxvi Contradictorio con lo expresado en otras fuentes, a tal cacique responderían muy pocos guerreros. Así el "más poderoso de entre ellos [no tenía más que (...)] 15 a 20 soldados o indios de los más expertos" (ALVEAR. 1900, p. 344 - 345).

En 1801, tras el combate del primer gajo del Tacuarembó el capitán Pacheco ordenó quemar 36 toldos. En la ocasión capturó 52 “infieles” pero, sin perjuicio de su triunfalismo, no es posible establecer cuántos murieron en combate o consiguieron escapar. ${ }^{\text {xxvii }}$ Poco antes, en el contexto de una misión de paz que acabó en hostilidad desde "un lado del arroyo Quarey (...) subido a un árbol, divisé como a distancia de diez cuadras, una pequeña toldería compuesta de 
dieciséis toldos (que según cuenta de las personas que suelen llenar el güeco de estos toldos, serían el número de setenta, más que menos". ${ }^{\text {xxviii }}$ No es claro si se está refiriendo a población total o a hombres de armas. Que la toldería fuera pequeña induce a creer lo primero. La capacidad de resistencia que demostraron sugiere lo segundo. Si así se asume, la cifra de personas por toldo podría acercarse a la que se ha visto en los casos precedentes. Por ello cabe conjeturar que en cada "estera" o "toldo" cohabitaban una decena o más de personas bajo parámetros de los que casi no han quedado indicios. Asimismo cabe suponer que una "toldería" media -y por lo tanto una parcialidad- constaba de unos treinta "toldos". En una relación de fin del siglo XVIII referida a la presencia de guenoa minuanos en San Borja los caciques parecen tener poder sobre un número más limitado de "vasallos"; no obstante en aquel tiempo y lugar debía haber grandes distorsiones en la organización social:

Don Lucas

Guênoà rehegua Caziques

Aba

Cuña

Cunumi

Miri be bae

Total

Don Caciquillo

Aba

Cuña

Cunumi

Miri be bae

Total

Don Josef

Aba

Cuña

Cunumi

Miri be bae

Total

Gueteboete minoanes
Voya [vasallos]

18

20

03

42

83

09

15

2

24

50

12

11

02

22

47

$190^{\mathrm{xxix}}$

Para aventurarnos al interior de un toldo es posible, como conjetura, referir a las circunstancias del cacique "menor" que en 1683 emigró a Santo Thomé siguiendo al padre García. Ello tiene la ventaja de remitir al principio del tiempo en que esa nación aparece con intensidad en las fuentes. Los parciales de ese cacique e incluso uno de sus hijos, quizás ya independiente, habrían quedado en libertad y en muchos casos no lo siguieron. Su "toldo" en cambio lo habría acompañado; en él cohabitaban 15 personas incluyendo a él mismo, "tres mujeres suyas, ${ }^{\mathrm{xxx}} \mathrm{y}$ su madre, un cuñado, hijos, y sobrinos, excelentes mozos" (GARCÍA, 1683 apud JARQUE, 1687, p. 374 - 382). 


\section{Caciques y "hechiceros".}

El padre García quiso persuadir a los guenoa minuanos del peligro que corrían frente a los portugueses de Colonia del Sacremento. Le "respondieron dos hechiceros, que harían bajar truenos, rayos, y tales tempestades, que los aguaceros llenasen los ríos, de suerte que inundados los campos, no podrían pisarlos sus enemigos \&c.". A ello el jesuita respondió "lo bastante para hacerlos callar" sin que al parecer eso contrariara a los caciques (GARCÍA, 1683 apud JARQUE, 1687, p. 1687: 374 - 382).

En encuentro posterior García $(1687$, p. 374 - 382) se refirió a los “disparates” de un hechicero, de fácil "impugnación”. A continuación "otro cacique principal, dijo, que nunca habían oído semejantes cosas, sobre las cuales debían volver a hablarse; porque materias tan graves pedían otra resolución, \&c" y ello evidencia que cuestionaba la autoridad religiosa de su chaman..

Similar desautorización de sus propios dirigentes religiosos parece desprenderse de un encuentro acontecido poco antes de la partida de García. El jesuita había convocado a los caciques buscando que no impidieran marchar a los que deseaban acompañarlo. Antes que "dijese palabra" un "hechicero" lo desafió a hacer "un milagro (...) Otros disparates proponía el hechicero, hasta que enfadado de oírle un cacique, le mandó callar, y se fue corrido" (1687, p. 374 - 382).

Sin embargo tales expresiones no pueden tomarse más que como indicios o, en todo caso, como reflejo de las percepciones de García. Por supuesto no parece a nuestro alcance recrear el diálogo que debió existir entre caciques y chamanes. No obstante estos últimos tienen que haber sabido, por ejemplo, que la resolución de los caciques en el sentido de alargar la estadía de García se debió a que “ellos más apetecían la yerba, y tabaco, que mis pláticas”. Así lo evidenciaba uno de los caciques "porque solo acudía al fin de las doctrinas, para entrar a la parte del regalo, que les daba" (1687, p. 374 - 382). Además, en lo que parece la jurisdicción de los individuos sobre sus parientes, uno de los "hechiceros" "salió pidiendo la paga por su hermano; yo le ofrecía lo que había dado a otros; pero él no se contentó, por lo cual hube de redoblar el precio, con que se fue; y entró su hermano mayor, muy enojado contra el dicho su hermano, por haber usado tal exceso conmigo, sin avisarle a él, que como mayor debía esperar su consejo"(1687, p. 374 - 382).

Al inicio de la década de 1730 el padre Miguel Jiménez trabajó con intensidad entre los guenoa minuanos “infieles”. Para ello se valió de aquellos que habían aceptado el cristianismo 
y pasado a vivir en los pueblos de misiones. Uno de ellos, llamado Borja fue al igual que el padre Jiménez atacado por un “hechicero”. Éste, tras golpearlos desistió de su propósito e instó a "Borja a quedar fiel al padre, y rogó a los dos encarecidamente que no dijesen nada de lo que había pasado, porque de seguro lo matarían los caciques al saberlo" (CARTA ANUA DE 1730 - 1734 EN MANUSCRITOS DA COLEÇÂO DE ANGELIS, 1955, p. 167). En parecido sentido se expresó el padre Lozano (1873 - 1875: I, 406), señalando que "tienen entre ellos algún séquito los hechiceros, pero no tanto que prevalezca a los caciques, quienes, según su antojo, contradicen a los magos, por más que se quieren hacer formidables con amenazas de tempestades, secas y semejantes castigos con que aterran al vulgo; pero son despreciados de los caciques, porque conocen su ningún poder y sobrados embustes".

\section{Caciques citados}

Algunos nombres de caciques han llegado hasta nosotros; los que se señalan a continuación no tienen más propósito que ordenar aquellos que se han mencionado en esta contribución. En ocasiones los nombres se repiten, quizás refiriendo a un mismo dirigente que en tal caso habría tenido actuación durante un lapso prolongado. En tal sentido el ejemplo más notorio es el del cacique Yaguareté.

Antonio: participó en la negociación de paz de 1763 con Montevideo.

Ayala: ver Miguel Ayala, don; también ver Zapata.

Balasán: su toldería estaba en las puntas de "Quarey" hacia principios de siglo XIX. ${ }^{\text {xxi }}$

Baruala: para eludir a las tropas procedentes de Montevideo se retiró hacia 1751 a los pueblos de misiones.

Batú: relevante en la década de 1780.

Beteté: relevante a mediados del siglo XVIII.

Canamazan: habría optado por mantener la paz con Montevideo a mediados de siglo XVIII; no obstante fue muerto por tropas procedentes de esa ciudad.

Carapé: relevante a mediados del sigo XVIII

Cloyan $^{\text {xxxii }}$ fue a San Borja en 1708 a pedido de los jesuitas.

Comandan: su toldería estaba en la costa del "Ybirapuitá" hacia principios del siglo XIX. ${ }^{\text {xxxiii }}$

Comiray, cacique “mayor" en la década de 1760.

Coraya: mató a otro cacique de su misma nación hacia 1730.

Coraya hijo de: sucedió a su padre como cacique. Estuvo entre los que escucharon la 
mediación del padre Jiménez en contexto de la guerra contra Montevideo.

Cumandat: principal en la búsqueda de acuerdo con Montevideo en 1762.

Francisco: en la segunda década del siglo XVIII negociaba con el gobernador de Colonia. $^{\text {xxxiv }}$

Gómez, Manuel: participó en la negociación de paz de 1762 con Montevideo.

Guayancay: escuchó la mediación del padre Jiménez en contexto de la guerra contra Montevideo. De nombre casi igual al que se cita a continuación y cuyo parentesco -si lo hubodesconocemos.

Gueyancaí: cacique sexagenario, cristiano, habría muerto en San Borja en 1728, donde estaba desde hacía muchos años.

Guitabuiabo, Agustín. Parece ser un capitán que estaba entre los guenoa minuanos en 1732 y no un cacique de esa nación.

Iaplemán: era hacia 1730 el Quireymbá o jefe principal hacia 1730.

Joaquín, don: antes de 1713 el gobernador de Buenos Aires ${ }^{\mathrm{xxxv}}$ lo había "agasajado y solicitado su conversión" sin que pueda asegurarse que en esa Ciudad. ${ }^{\text {xxxvi }}$

Leandro: habría estado en Buenos Aires en 1714. ${ }^{\text {xxvii }}$

Lescano, Jph Luis: participó en la negociación de paz de 1762 con Montevideo.

Lorenzo: participó en la negociación de paz de 1762 con Montevideo.

Loya: se le atribuyó mando sobre 1.200 individuos. En la segunda década del siglo XVIII negociaba con el gobernador de Colonia. Quizás era el hermano de la mujer cuyo regreso se negociaba. ${ }^{\text {xxxviii }}$

Lucas, don: fue a Candelaria, de las misiones, en la década de 1790.

Macadar: en la segunda década del siglo XVIII negociaba con el gobernador de Colonia. ${ }^{\mathrm{xxix}}$

Macedar: tío del cacique Loya. No es claro si era cacique. En la segunda década del siglo XVIII negociaba con el gobernador de Colonia. Quizás era el tío de la mujer cuyo regreso se negociaba. ${ }^{\mathrm{xl}}$

Maulein: relevante en la década de 1780:

Mauná: se rindió a las tropas de Montevideo en 1751.

Miguel Ayala, don: caraí. “rey” según Porto (1954) en la década de 1780.

Molina: participó en la negociación de paz de 1762 con Montevideo.

Moreira, Moreiras o Moreyras: relevante durante la guerra guaranítica; acusado de duplicidad.

Naaguaygat: jurado enemigo de los españoles hacia 1730; parece el mismo que Nolagua 
y guat.

Olaya: el gobernador Zabala lo mencionó como cacique de los guenoa minuanos en 1721.

Pastau: el más anciano de los caciques que escucharon la mediación del padre Jiménez en contexto de la guerra contra Montevideo.

Pedro: escuchó la mediación del padre Jiménez en contexto de la guerra contra Montevideo.

Quiritó, Christobal: participó en la negociación de paz de 1762 con Montevideo.

Salteinho: relevante en la década de 1780. Posiblemente fuera el "Salteño" que se anota a continuación.

Salteño: participó en la negociación de paz de 1762 con Montevideo.

Tacú: fue en 1732 a Montevideo para celebrar el tratado de paz.

Tajuy: relevante en la década de 1780 .

Usa, Francisco. Parece ser un capitán que estaba entre los guenoa minuanos en 1732 y no un cacique de esa nación.

Vetete: ver Beteté:

Yaguareté: mencionado en la carta del padre García del año 1683. Alguien de igual nombre fue relevante en episodios de la guerra de los años 1701 - 1702 y se retiró a San Borja, lo cual podría ser indicio de que se trataba del mismo individuo. En el año 1708, durante el breve ciclo de hostilidad entre sociedad jesuítico misionera y guenoa minuanos los primeros derrotaron a la gente del cacique Yaguareté en las cabeceras del Piraí Guazú. Habría ido a Buenos Aires en 1714. ${ }^{x l i}$ También un cacique así llamado fue mencionado en 1732. Es improbable pero no imposible que estemos ante el mismo individuo en cuyo caso habría sido cacique durante medio siglo.

Zapata, Miguel, velho: padre de caraí Miguel Ayala. No parece cacique.

\section{¿Cacicas?}

Como ya se ha expresado las fuentes adolecen de sesgos y limitaciones que impiden conocer relevantes aspectos de la organización social de los guenoa minuanos. Ello es especialmente intenso en el caso de las mujeres. Por ejemplo, faltan documentos referidos a la poliandria que cabe suponer existió cuando se dieron contextos de enorme desigualdad de género. ${ }^{x \text { lii }}$ Las fuentes en cambio se refirieron repetidas veces la poliginia la interior de esa nación. Ya se ha visto que el "cacique menor" que emigró con el padre García en 1683 lo hizo 
con "tres mujeres suyas". Un siglo más tarde Saldanha afirmó que eran "cazados com varias mulheres, em o numero de duas até cinco". xliii Las fuentes no permiten asegurar que la poliginia estuviera reservada a los caciques; tampoco informan sobre los procesos -si así ocurrió- por los cuales las abandonaban quienes aceptaron el cristianismo. ${ }^{x \text { liv }}$ También permanece en la oscuridad la suerte de aquellas que en el contexto del cambio de cultura habrían sido repudiadas. ${ }^{x l v}$ Ocasionalmente en la documentación colonial se empleó el término "cacica"xlvi aunque no hay indicios de que las haya habido entre los guenoa minuanos. Algunos documentos sugieren que las mujeres de esa nación gozaban de posibilidades de elección así como de elevada consideración entre los suyos. Así, como ya se ha visto, entre los que emigraron siguiendo al padre García en 1683 un "muchacho cacique retrocedió, desistiendo del "del viaje porque su su madre viuda (...) no había querido acompañarle”. Refiriendo al ámbito de los lazos familiares y /o afectivos, para los que las fuentes son singularmente parcas, puede mencionarse un suceso vinculado a la evacuación de Colonia del Sacramento a principios de 1705. En ese contexto de crisis -por lo tanto no podemos saber si de grado o por fuerza- marchó con ellos una mujer guenoa minuana. Una década más tarde los portugueses retomaron control de esa Plaza; entonces caciques guenoa minuanes les ofrecieron toda suerte de adhesión a cambio de volver a verla. ${ }^{\text {xlvii }}$

En 1762 en Montevideo, Petrona, guenoa minuana, hizo de intérprete a quienes llegaron a esa ciudad buscando un acuerdo para establecerse en su jurisdicción. Era "ya cristiana, y hermana" de uno de los caciques que había llegado buscando el acuerdo. (ACTAS DEL CABILDO DE MONTEVIDEO: III, p. 390 - 393). En similar tiempo y lugar un hermano del cacique principal Cumandat solicitó permiso para pasar a vivir en Montevideo "por tener aquí su mujer". xlviii

Al menos hacia la década de 1780 los que tenían aperos para montar "somente sâo os cassiques e as suas mulheres"xlix $\mathrm{Y}$ ya durante las guerras civiles que marcaron el fin del denominado período colonial Larrañaga tuvo ocasión de tratar caciques minuanes que acompañan y aman tiernamente al jefe de este ejército: uno de ellos comió con su mujer en la mesa del general [Artigas], habiendo dejado en su toldería otras mujeres suyas" (INSTITUTO HISTÓRICO Y GEOGRÁFICO DEL URUGUAY, 1925: III, p. 174 - 175).

\section{Territorio, Arqueología e Historia}

La reconstrucción histórico-arqueológica del territorio guenoa implica -entre otras variables- analizar el rol que desempeñaron los caciques así como caracterizar los escenarios 
sobre los que ejercieron su dominio. El territorio es el espacio geográfico gestionado por un grupo humano, que explota y reclama derechos sobre sus recursos naturales. En él se disponen de modo estratégico las unidades sociales (familiares y/o políticas) que lo sustentan. Este territorio es defendido y reivindicado en exclusividad; sobre él se imprime un relato simbólico propio al tiempo que se consagra un lugar para enterrar los muertos.

La arqueología presenta evidencias de continuidad histórica y geográfica entre las sociedades precoloniales que construyeron "cerritos" en las tierras inundables y la nación guenoa minuan que allí fue preponderante desde que hay documentación hasta principios del siglo XIX (LÓPEZ MAZZ; BRACCO, 2010). Los paisajes antrópicos con monumentos y lugares formales de función funeraria del territorio guenoa minuan cruzan la historia con la geografía por más de 5000 años (LÓPEZ MAZZ, 2001; GIANOTTI, 2015). Los procesos de larga duración en el que se desarrollan y transforman estos paisajes antrópicos están marcados por la preferencia en la explotación de los recursos de las tierras anegadizas. Tales preferencias marcaron las estrategias político territoriales implementadas por los caciques.

Los límites máximos de expansión del sistema mundi guenoa minuan (sensu WALLERSTEIN, 1999) estarían comprendidos entre las misiones jesuíticas del alto río Uruguay, la desembocadura de ese mismo río, el estuario del Plata, el océano Atlántico, la cuenca de la Laguna Merín y la desembocadura de la de los Patos. (BRACCO, 1999). Abundante documentación reporta la presencia de caciques minuanos con sus grupos en ese espacio durante un dilatado lapso. Sin perjuicio de distorsiones derivadas de los sesgos en las fuentes, las nacientes de los ríos Negro y el Piraí parecen ser en ocasiones epicentro del poder de esa nación (LÓPEZ MAZZ; BRACCO, 2010, p. 282).

Los diferentes cacicazgos o parcialidades habitaban en sus respectivos territorios. Como ya se ha visto la nación tenía un cacique principal y otros subordinados, probablemente jefes de familias extensas, padres y tíos de cazadores y eventualmente de guerreros. Los paisajes funerarios de ese espacio (con miles de años de continuidad) sugieren que los caciques habitaban lugares al que estaban vinculados históricamente por su genealogía de carácter patrilineal. La actividad ganadera rápidamente asumida hizo que cuando eran convocados varios caciques (transformados ya en pastores) acamparan a una distancia suficiente unos de otros, como para que no se les mezclara el ganado. La situación descrita se ajusta al modelo de sociedad heterárquica propuesto por Crumley (1995) originalmente para sociedades constructoras de montículos de tierras bajas del norte de Europa, pero también para esta región (LÓPEZ MAZZ, 2001; GANOTTI, 2015). Estas sociedades unidas por vínculos históricos, se mantenían autónomas cada una en su territorio (campos de invernada) y podrían cooperar entre 
ellas frente a la amenaza de peligro externo. Pero también tener disenso y conflictos, originando enemistades históricas al interior de la misma tradición cultural.

La comunicación a distancia entre estos grupos relativamente autónomos estaba articulada por un complejo sistema de señas con fuegos, humos y resplandores. También por "vicheadores" o "bomberos", vigías ubicados de modo estratégico en los puntos altos de las sierras donde hay máxima visibilidad. De esta manera los caciques estaban cada uno en su territorio, pero al corriente de lo que sucedía en la región. Así, en poco tiempo se podía trasladar un mensaje a cientos de kilómetros y convocar a una reunión de caciques.

Como ya se ha visto, la gestión guenoa-minúan del ganado está documentada al menos desde la década de 1680. El territorio guenoa minuano se vio muy alterado con la fundación de Montevideo que, entre otras cosas provocó el desplazamiento de los caciques Carapé y Betete hacia las sierras de Maldonado. Entre 1721, oficiales reales denuncian al Rey de España el contrabando portugués de ganado, en todo el territorio con particular concentración en la zona este de Uruguay," (...) han hecho y hacen faenas de corambres de toros ayudados de los indios infieles nombrados de minuanos (...) quienes teniendo como han tenido siempre su habitación en Castillos". ${ }^{1}$ En esa fecha, desde Buenos Aires reclaman al Rey que los portugueses" (...) hacen excesivas faenas, y que tienen al presente para esas faenas (...) y la ayuda de una nación de indios bárbaros que en aquellos parajes habita llamados minuanes". li

Por el norte la presencia guenoa minuana fue reportada desde mediados del siglo XVII en las Misiones (San Borja, de la Cruz, San José, Jesús María, San Tomé) y en las nacientes de los ríos Negro y Piraí (LÓPEZ; BRACCO, 2010). En el noroeste los guenoa minuanes tenían lugares sagrados donde venían a realizar rituales iniciáticos en las nacientes del Arapey y al noreste enterraban a sus muertos en las sierras de Aceguá (FURLONG, 1936: mapa 24). Otros lugares de enterramiento del grupo minuano fueron señalados en proximidades de la sierra de Ycabacuá (SALDANHA, 1938), en el cerro Tupamabaé de las sierras de Maldonado al lado del cerro del cacique Betete (FIGUEIRA, 1958) en la Sierra de San Miguel (BAPTISTA DE OLIVEIRA, 1850) y en el cerro Sepulturas a proximidad del cerro Marmarajá (VARELA ULLOA, 1911) La arqueología reconoce mayor profundidad temporal para esta práctica, según se documentó en los cerritos de indios de India Muerta, San Miguel, laguna Negra, Castillos y Chafalote que incluyen zonas de enterramientos humanos usadas desde la prehistoria (ca 2000 años a.p.) hasta el siglo XV (LÓPEZ MAZZ, 2001).

El eje de desplazamiento sureste - noroeste está bien documentado para el período histórico, aunque para entonces los parámetros de movilidad estaban muy alterados por la introducción de fauna de origen europeo. Ese eje es muy antiguo y está documentado en la 
prehistoria por los grupos de la cuenca de la laguna Merín que iban al norte a aprovisionarse de piedras de buena calidad para tallar sus puntas de proyectil (LÓPEZ MAZZ, 2017).

El avance de la sociedad colonial, especialmente desde Montevideo, Rio Grande y río Pardo fueron debilitando el control territorial de estos caciques minuanos. Ello los habría impulsado hacia áreas anegadizas (entre el Cebollatí y el Olimar) habitando en sus ranchos de arco, plantando porotos, haciendo cerámica y corambre según relata el sargento Prieto en 1780 (en MARTÍNEZ ROVIRA, 1982, p.75) También al parecer se refugiaron en las sierras, donde desarrollaban la ganadería y aún podrían controlar el tránsito regional (SOTELO, 2018).

Los guenoa minuanos - de acuerdo a la evidencia arqueológica - habrían tenido una estrategia de caza racional de ciervos que les facilitó la rápida adopción de la ganadería. A principios del siglo XVIII negociaron con los jesuitas el mayor traslado de ganado bovino registrado en fuentes históricas: unas 450000 cabezas que fueron extraídas de la vaquería del mar (BARRIOS PINTOS, 1967). No obstante la entidad del manejo de ganado, todavía en 1750, para la zona de Chafalote, Castillos y laguna Negra Francisco Gorriti se señalaba que era "habitación común de los minuanos a temporadas por la mucha caza de ciervos que hay en él" (en MARTÍNEZ ROVIRA, 1982, p. 44) Los corrales de palma asociados al llamado camino de la costa, ilustran un periodo de clara participación indígena en el control del ganado (DAVEZIES, 2019)

En 1769 el militar José de Soria, ejecutando el plan de poblamiento de Francisco del Puerto, ocupó y reclamó en Buenos Aires una extensión territorial de unas 120000 hectáreas próximo a la Laguna Negra (LÓPEZ MAZZ et al. 2019) Esa estancia está asociada al "camino del indio”, una vía de tránsito prehispánica que permitía atravesar un territorio poblado por los caciques minuanes de Castillos, que habrían producido numerosos "cerritos de indios" (LÓPEZ MAZZ, 2001; GIANOTTI, 2015) Acá se establece un frente de avance colonial (BASILE BECKER; PARIS, 1977) que poco a poco irá expulsando a los caciques minuanes hacia el norte, hacia la zona del "mato castellano" en el alto río Uruguay, las nacientes del río Negro y del Piraí. Esta frontera ha sido tradicionalmente descrita como una línea entre los imperios portugués y español. No obstante, recientes investigaciones (ERBIG, 2015) sugieren que esa imagen de la frontera es una construcción hecha desde la óptica de los centros de poder colonial. Esa mirada en nada responde a una realidad dominada por la instalación de plazas fuertes coloniales en medio de un "desierto" dominado por caciques minuanes ganaderos, que desde sus tolderías reclamaban un derecho natural al usufructo de la tierra y sus recursos.

El sistema jeráquico entre caciques se mantuvo durante dilatado lapso. En la década de 1780 según Aurelio Porto (1954, p. 70) era "rei D. Miguel Caraí, que foi o último dos minuanos 
e o primeiro gaúcho do campo. Interessante retraçar a figura deste produto inicial do cruza mento que será o ponto de transição entre a barbaria minuana e a civilização nascente do branco, em terras do Rio Grande do Sul. Quando os primeiros portugueses palmilharam o litoral, para da Laguna alcançar a Colónia do Sacramento, recém-fundada no Prata (1680) em um dos afluentes do Cebolati, conhecido por Zapata ou Ayala, que fica a 369 6' 37" de lat. S., encontraram estabelecido um paraguaio de origem espanhola desse nome e apelido, D. Miguel Ayala, mais conhecido por Velho Zapata. Era filho desse Velho Zapata e de uma minuana, D. Miguel Ayala, ou D. Miguel Caraí, último rei dos minuanos, referido também por Saldanha, Alvear, Azara e outros demarcadores".

Tal circunstancia fue también señalada por el demarcador Alvear (1900). En su diario indicó que los guenoa minuanos se dirigían "por las órdenes de un indio principal que llaman cacique. Los caciques están a más de esto subordinados y siguen la voz de otro de mayor fama que hace cabeza, el que en la actualidad era un tal Miguel Ayala, hijo natural de un vecino antiguo de Santiago del Estero llamado viejo Zapata, de quien ya dijimos que moró largo tiempo hacia aquel pequeño arroyo que lleva su nombre, y desagua en la Laguna de Merín" (ALVEAR, 1900, p. $344-345)$.

En un trabajo previo mostramos que los lugares donde habitaban los indios minuanes o que conservan un topónimo minúan coincidían espacialmente con la presencia del sitio arqueológico conocido como "cerrito de indio" (LÓPEZ MAZZ; BRACCO, 2010). Tales son estructuras en tierra producto de la actividad doméstica y/o funeraria. En ese sentido y siguiendo el diario de Saldanha (1938) un equipo de investigadores localizó la antigua residencia de don Miguel Caraí Ayala entre los arroyos Zapata y Ayala, ambos afluentes de la laguna Merín. El antiguo asentamiento es lugar donde existe un conjunto de cerritos de indios

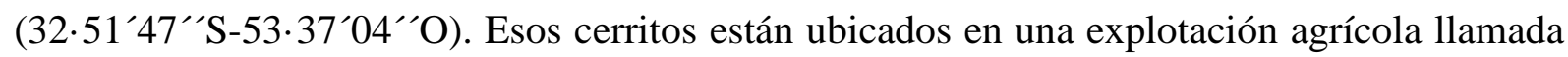
"Arrocera Zapata"; allí nos informaron que el nombre era en memoria del padre del Caraí Miguel Ayala.

Recientemente, también siguiendo los diarios de las partidas demarcadoras de límites del tratado de San Idelfonso, un equipo de investigadores consiguió identificar cerritos de indios

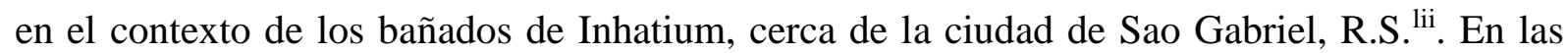
cercanías de ese lugar se realizó en 1787 el encuentro entre el demarcador Saldanha (1938) y el grupo de caciques del que formaba parte Miguel Caraí Ayala. Los hallazgos reafirman el vínculo histórico entre los cerritos de indios y los grupos guenoa minuanos; asimismo entre estos y las tierras inundables. ${ }^{\text {liii }}$ También ilustra un eje de movilidad y tránsito suereste-noroeste, a través del cual se movían los grupos minuanes, como lo muestra la propia peripecia de Don 
Miguel Caraí Ayala.

\section{Referencias bibliográficas}

ACOSTA Y LARA, Eduardo F. La guerra de los charrúas. Montevideo - Buenos Aires: Talleres de Loreto Editores, 1998.

ALVEAR, Diego de. Diario de la segunda subdivisión de límites española. Anales de la Biblioteca, Tomo I. Publicación de documentos relativos al Río de la Plata. Con introducción y notas de P. Groussac. Buenos Aires: Imprenta y Casa Editora de Coni Hermanos, 1900. Recuperado en agosto de 2019 de <https://www.biblioteca.org.ar/libros/130485.pdf>. ARCHIVO ARTIGAS (1950 - 2006) Vol. I a XXXVI. Comisión Nacional Archivo Artigas. Montevideo.

AVELLANEDA, Mercedes. Ruptura de la alianza Jesuita-Guaraní y su reconstrucción a mediados del siglo XVIII.. En Historia Paraguaya, vol.L. 2010. p. 313-341.

BASILE BEKCER, Itala y Juana Pais. Os indios da Banda Oriental charrúa e minuano, histórico abastesemento e assentamento e sua relaçao com as frentes de expançao. Quinto encuentro de Arqueología do Litoral, p .89-110, Fray Bentos, 1977.

BAPTISTA DE OLIVEIRA, Cándido. Reconhecimento topográfico da fronteira do Império do Brasil na Província de São Pedro do Rio Grande do Sul. Instituo Histórico e Geográfico Brsileiro, Porto Alegre, 1850.

BARRIOS PINTOS, A.. De las vaquerías al alambrado: contribución a la historia rural uruguaya. Montevideo: Nuevo Mundo, 1967.

BRACCO, Diego. Guenoas. Ministerio de Educación y Cultura. Montevideo, 1999.

Charrúas, guenoas y guaraníes. Interacción y destrucción: indígenas del Río de la Plata. Montevideo: Linardi \& Risso, 2004.

Con las armas en la mano: charrúas, guenoa-minuanos y guaraníes. Montevideo: Editorial Planeta, 2013.

“Charrúas y guenoa-minuanos: caballos, mujeres y niños". Temas Americanistas No. 33: 113 - 129. Revista del Departamento de Historia de América de la Universidad de Sevilla. 2014. Sevilla.

"Charrúas y aculturación: la primera década en Concepción de Cayastá"

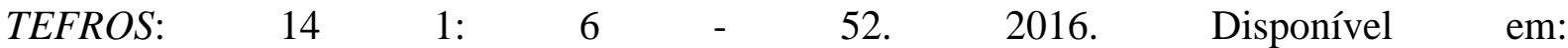


<http://tefros.equiponaya.com.ar/revista/index.htm>. Acesso em 12 jul. 2019.

CASTRO E ALMEIDA, Eduardo. Inventario dos documentos relativos ao Brasil existentes no Archivo de Marinha e Ultramar de Lisboa. Organizados para a Biblioteca Nacional do Río de Janeiro. 8 Vol. Río de Janeiro, 1913 - 1921.

CRUMLEY, Carole. Heterarchy and the Analysis of Complex Societies. Robert Ehrenreich, Carole Crumley y Janet Levy, eds. Archeological Papers of the American Anthropological Association 6 (1): 1-5. 1995.

DABEZIES, J. M.. Negotiating the Taskscape. Relocating Human - Environmental Relationships in Conservation Proposals around Palm Forests in Uruguay. Conservation and Society, 17(3), 2019, p. 236-249.

ERBIG, J. Imperial lines, indigenous lands: transforming territorialities of the Río de la Plata, 1680-1805 (Tesis Doctoral) Universidad de North Carolina, Estados Unidos. 2015. Disponível em: $\quad$ https://www.jeffreyerbig.com/uploads/2/0/4/0/20408503/dissertation_erbig.pdf>. Acesso em 21 ago 2019.

FIGUEIRA, José Joaquín. Excursión arqueológica al cerro Tupambay, realizada a comienzos de 1881. Aparatado de la Revista Nacional, Tomo II, 1958, Número III:11-126. Montevideo.

FURLONG, Guillermo. Cartografía jesuítica en el Río de la Plata. Buenos Aires: Jacobo Peuser, 1936.

JARQUE, Francisco (1687) Insignes Misioneros de la Compañía de Jesús. Pamplona: Juan Micon Editor, 1687.

FRADKIN, Raúl O. La revolución en los pueblos del litoral rioplatense / Revolution in the towns of Río de la Plata Coast. Estudos Ibero-Americanos, PUCRS, v. 36, n. 2, p. 242-265, jul./dez. 2010. Disponível em: <https://core.ac.uk/download/pdf/25529842.pdf〉. Acesso em 12 ago. 2019.

FRÍAS, Bernardo. Historia del General Martín Güemes : y de la provincia de Salta, o sea de la Independencia. Salta: EUCASA, 2018.

GIANOTTI, Camila. Paisajes sociales, monumentalidad y territorio en las tierras bajas de Uruguay. (Tesis de Doctorado). 2015. Universidad de Santiago de Compostela. Disponível em: <https://minerva.usc.es/xmlui/handle/10347/13757>. Acesso em 22 ago 2019.

JACKSON, Robert H. A Population History of the Missions of the Jesuit Province of Paraquaria Newcastle: Cambridge Scholars Publishing, 2019. 
LÓPEZ MAZZ, José. Las estructuras tumulares (cerritos) del litoral atlántico uruguayo. Latin America Antiquity, vol.12, No.3, 2001, p. 231-255.

Silcrete procurement system in Uruguay Prehistory. Journal of Archaeological Repport, vol 15, 2017, p. 561-569.

LÓPEZ MAZZ, José M.; BRACCO, Diego. Minuanos: apuntes para la geografía e historia del territorio guenoa-minuan. Montevideo: Editorial Linardi \& Risso, 2010.

LÓPEZ MAZZ, José; MARÍN, Carlos; DAVEZIES, Juan; TEJERIZO, Carlos “Arqueología de la esclavitud africana en la frontera uruguayo-brasileña: el caso de la Estancia de los Correa (Rocha, Uruguay)" en Revista de Arqueología, Buenos Aires. En prensa. 2019.

LOZANO, Pedro. Historia de la Conquista del Paraguay, Río de la Plata y Tucumán. 5 Vols. Buenos Aires: Editada por Andrés Lamas, 1873 - 1875.

Manuscritos da Coleçâo de Angelis (1955) / VI / Antecedentes do Tratado de Madri: jesuitas e bandeirantes no Paraguay (1701 - 1751). Introduçâo, notas e sumário por Jaime Cortesâo. Rio de Janerio. Biblioteca Nacional, Divisâo de obras raras e publicaçôes. Ànuas do Paraguai. Ânua relativa as missôes do Parana, Uruguai e dos Chiquito, entre os anos de 1730 a 1734. Disponível em: <http://objdigital.bn.br/acervo_digital/div_manuscritos/mss1019247/mss1019247.pdf>. Acesso em 13 ago. 2019.

MARTÍNEZ ROVIRA, E. Entre el olvido y la memoria. Montevideo: UdelaR, 1982.

MAYO, Carlos A. Estancia y sociedad en la Pampa. Buenos Aires: Editorial Biblos, 2004.

PORTO, Aurelio. História das Missöes Orientais do Uruguai. Primeira parte. Porto Alegre:

Ediçäo da Livraria Selvach, 1954 Disponível em: <https://archive.org/stream/historiadasmisso01port/historiadasmisso01port_djvu.txt>. Acesso em 23 ago. 2019.

Revista del Archivo General Administrativo: o colección de documentos para servir al estudio de la historia de la República Oriental del Uruguay (1885 - 1943) / patrocinada por el gobierno y dirigida por Pedro Mascardó. Archivo General de la Nación (Uruguay). Imprenta El siglo Ilustrado. Montevideo, 1885 - 1943.

Real Academia Española (1729) Diccionario de la lengua castellana, en que se explica el verdadero sentido de las voces, su naturaleza y calidad, con las phrases o modos de hablar, los proverbios o refranes, y otras cosas convenientes al uso de la lengua [...]. Compuesto por la Real Academia Española. Tomo segundo. Que contiene la letra C. Imprenta de Francisco del Hierro. Madrid. Disponível em:

<http://www.rae.es/recursos/diccionarios/diccionarios-anteriores-1726-1992/nuevo-tesorolexicografico>. Acesso em 21 jul 2019. 
SALDANHA, José de. Diario resumido e histórico (1786 - 1787) Anais da Biblioteca Nacional de Rio de Janeiro, vol. 51, 1938. Ministerio de Saude e Cultura. Rio de Janeiro. Disponível em <http://memoria.bn.br/pdf/402630/per402630_1929_00051.pdf>. Acesso em 23 jul 2019.

SARMIENTO, D. F. Conflicto y armonías de las razas en América. Buenos Aires: Imprenta de D. Túñez, 1883.

SCHULZ PRAIA, Felipe. Para que cada Pueblo se govierne por si: modernidade política e atores indígenas naregião do Rio da Prata (1810-1821). Universidade Federal do Rio Grande do Sul. Instituto de Filosofia e Ciências Humanas. 2017. Departamento de História. Programa de Pós-Graduaçâo em Histórica. Disponível em:

<https://www.academia.edu/39148991/Para_que_cada_Pueblo_se_govierne_por_si_modernid ade_pol\%C3\%ADtica_e_atores_ind\%C3\%ADgenas_na_regi\%C3\%A3o_do_Rio_da_Prata_1 810-182>. Acesso em 12 ago. 2019.

SOTELO, Moira. Paisajes olvidados en las sierras de Uruguay. Arquitectura en piedra en la sierra de Aguirre. Tesis de Doctorado, Universidad de Sevilla. 2018. Disponível em: <https://digital.csic.es/bitstream/10261/173705/1/Tesis\%20Doctoral_Moira\%20Sotelo\%20Ri co.pdf>. Acesso em 15 ago. 2019.

VARELA ULLOA, José. Diario de la partida demarcadora de límites entre España y Portugal. 1911. Disponível em: <http://wwwlib.unc.edii/ik/>. Acesso em 21 ago. 2019.

WALLERSTEIN, Immanuel. The Modern World-System II: Mercantilism and the Consolidation of the European World-Economy, 1600-1750. New York: Academic Press, 1980. WEBER, David J. Bárbaros: los españoles y sus salvajes en la era de la Ilustración. Traducción castellana de Alejandra Chaparro y Luis Noriega. Barcelona: Editorial Crítica, 2007. Wilde, Guillermo (2009) Religión y poder en las misiones de guaraníes. Buenos Aires. Editorial $\mathrm{Sb}$.

Submetido em: 01/11/2019

Aprovado em: 12/12/2019

Publicado: 23/12/2019

\section{Notas}

\footnotetext{
* Doutor pela Universidade de Sevilha. Docente da Universidad de la República/ Facultad de Humanidades y Ciencias de la Educación - UDeLaR / CUT. E-mail: dbracco@ hotmail.com

* Doutor em Arqueologia. Professor da Universidad de la República de Uruguay. Professor convidado da Universidad Autonoma de Barcelona, Universidad de Sao Paulo e Universidad del Centro de la Provincia de Buenos Aires. Membro da Comision Nacional del Patrimonio Cultural (Ministerio de Educacion y Cultura de Uruguay). E-mail: lopezmazz@yahoo.com.ar
} 
La carta del padre Francisco García es una fuente de valor extraordinario. Está fechada en Santo Tomé el 10 de diciembre 10 de 1683, a su regreso de la entrada a los "bárbaros guanoás". Fue transcripta en la citada obra de Francisco Jarque (1687: 374 - 382). En el presente artículo se cita: (García 1683 en Jarque 1687: 374 - 382) ii

Archivo General de Indias (En adelante A.G.I.) Charcas 261. Carta del padre Alonso del Castillo. Yapeyú, junio veinte de mil seiscientos y ochenta y ocho.

iii

A.G.I., Chile, 153. Fray Pedro Jerónimo de la Cruz. Buenos Aires, 15 de setiembre de 1726.

iv

A.G.I., Charcas 214. Zabala al Rey. Buenos Aires, 30 de abril de 1731.

V

Carta del Padre Miguel Ximénez, de 10 de agosto de 1731, transcrita por el padre Pedro Lozano al padre Procurador general Sebastián de San Martín, Córdoba de Tucumán, 30 de enero de 1732. Biblioteca Nacional Madrid. Ms. No 12.977 34: 26 - 28.

vi

Aunque el motivo de la mediación era el cese de las hostilidades entre la recién fundada Montevideo y los guenoa - minuanos, el Quereimbá ejercía su dominio desde "la otra banda del [río] Piraí. Tal alcanzaba a los que estaban cerca de la Ciudad asediada y a los que se habían "recostado" a los pueblos de misiones. Carta del Padre Miguel Ximénez, de 10 de agosto de 1731. Biblioteca Nacional - Madrid. Ms. º 12.977 34: 26 - 28. vii

Carta del Padre Miguel Ximénez, de 10 de agosto de 1731, transcrita por el padre Pedro Lozano al padre Procurador general Sebastián de San Martín, Córdoba de Tucumán, 30 de enero de 1732. Biblioteca Nacional Madrid. Ms. No 12.977 34: 26 - 28.

viii

Paz de los indios minuanos. San Felipe de Montevideo, marzo 22 de 1732. Archivo General de la Nación Argentina (en adelante A.G.N.A.) IX 208 6. (Archivo Artigas 1950: 70 - 71).

ix

Actas del Cabildo de Montevideo. 29 de marzo de 1762.(Revista del Archivo General Administrativo: 1885 - 1943. Tomo III, pp. 288 - 293).

$\mathrm{x}$

Idem.

xi

Saldanha, José de (1938) Diario resumido e histórico (1786 - 1787) Anais da Biblioteca Nacional de Rio de Janeiro, vol. 51, año 1938. Ministerio de Saude e Cultura. Rio de Janeiro. Disponible en http://memoria.bn.br/pdf/402630/per402630_1929_00051.pdf Noticia sobre los minuanos. Por deficiencias en la versión digital tomado de Acosta y Lara (1998: 248 -251).

xii

Alvear, Diego de. Diario de la segunda subdivisión de límites española. Recuperado en agosto de 2019 de https://www.biblioteca.org.ar/libros/130485.pdf [El pdf referido indica páginas 344 y 345. No señala si se ha hecho a partir del original ni, en este caso, su ubicación. Posiblemente se realizó a partir de: (Alvear 1900). xiii

Archivo General de la Nación Uruguay (en adelante A.G.N.) Colección Pivel Devoto Tomo I, Caja 3, Carpeta 10. Diario de Juan Bentura Isfrán con lo acontecido a su expedición desde 10 de marzo hasta 10 de junio de 1800 .

xiv

José Antonio Martínez al conde da Figueira. Campamento da Figueira en Belén, marzo 30 de 1820. Archivo Público de Río Grande del Sur. 2a Sección. Museo "Julio de Castilhos". Porto Alegre. Brasil. Autoridades Militares. Caja No 201. Documento No 57B. Año 1820. En Archivo Artigas. Comisión Nacional Archivo Artigas. Tomos I a XXXIII. Montevideo, 1950 - 2001, tomo 36, pp. 330 - 332, doc. № 284. Adicionalmente Bracco (2015). $\mathrm{xv}$

Que fuera "pariente" y supiera la lengua de los guenoa minuanos no permite afirmar con certeza pero induce a creer que Manduré pudo ser guenoa minuan. Parentesco e idioma quedan evidenciados en carta de Lecor a Thomaz Antonio de Villanova Portugal, Montevideo, marzo 12 de 1820.

"Ill. mo e Ex. m0 S. or

Havendo-se, pouco depois da Batalha de Taquarimbó resolvido os Indios da tribu minuana, a deixar o partido de Artigas, e aprocurar o amparo da Armas de Sua Magestade; mais ainda receosos de que os Portuguezes, que occupáo esta Provincia fossem o que Artigas lhes pintava, mandáráo primeiramente ao Rincáo das Galinhas, 
dous individuos da sua confianca, e que se disiáo Secretarios dos dous Caciques Rondeau, e Artigas (assim chamados de seus respectivos Padrinhos, que süo D. n Jozé Rondeau, e D. n Manoel Artigas) solicitando paz, e amizade com os Portuguezes.

O Ex. mo General Curado, e o Brigadeiro Saldanha, lhes fiseráo todo o agasalho, e alguns presentes, que podéráo offerecer-lhes, e os despediráo contentes; e que assegurassem aos seus Chefes, o muito que os Portuguezes prezaváo as suas relacoens; e como prova de destincáo, os mandavao acompanhar pelo Tenente Coronel Manduré, que sendo aparentado com elles, e seu Amigo, sabendo a sua lingua, e estando muito reconhecido á consideracáo, que the havemos dado, era natural, que lhes falasse em pro da Nacao, e os ligasse mais a nos.

Com effeito nos fins de Fevereiro pp. ${ }^{\circ}$, o Tenente Coronel Manduré, se recolheu daquella diligencia trasendo em sua companhia ao Cacique principal Rondeau, seguido pelo seu Sargento Maior, e Ajudante, e que ratificando quanto pelos seus Emissarios havia proposto, quiz alem disso, que para melhor constarse lavrasse o termo incluso, que por elle foi afirmado com a signal da S. ta Cruz, por que nao sabe escrever.

Archivo Nacional de la Torre do Tombo. Lisboa. Portugal. Ministerio de Negocios Extranjeros. Colección de Despachos al Señor Márquez de Marialva. Legajo 56. Tomo II. Años 1818-1820. En Archivo Artigas (2006: $322-323)$.

xvi

A.G.I., Charcas 261. Carta del padre Alonso del Castillo. Yapeyú, 20 de junio de 1688.

xvii

Arquivo Colonial Ultramarino. Lisboa. Colonia do Sacramento, papeis avulsos, 1722. El gobernador de Colonia, Antonio Pedro de Vasconcellos al Rey. Colonia, 15 de octubre de 1722. En cualquier caso no puede descartarse que las desavenencias entre los caciques no fueran más que actuación delante del gobernador para obtener el máximo provecho.

xviii

A.G.I., Buenos Aires, 42. Zabala a José Patiño. Buenos Aires, 8 de mayo de 1733.

xix

El padre Lozano al procurador general Sebastián de San Martín. Córdoba de Tucumán, 30 de enero de 1732. Precede a carta transcripta del padre Miguel Ximénez entre fs 26 y 28. Biblioteca Nacional - Madrid. Ms. $\mathrm{N}^{\circ} 12.97734$.

$\mathrm{xx}$

A.G.N. Colección Pivel Devoto Tomo I, Caja 3, Carpeta 10. Diario de Juan Bentura Isfrán con lo acontecido a su expedición desde 10 de marzo hasta 10 de junio de 1800 .

xxi

Arquivo Histórico Ultramarino. Lisboa. Consulta al Consejo. Lisboa, 3 de setiembre de 1718. Río de Janeiro, doc. $\mathrm{N}^{\circ} 3580$.

xxii

A.G.N.A. IX-41-1-3. exp. 1, fs. 235 - 240. El cabo de la guardia de San Juan, Fco. de Pedraza al gobernador Prado y Maldonado. “De esta boca del río de San Juan”, 26 de diciembre de 1701.

xxiii

A.G.N.A. XI-41-1-3. exp. 4. Declaración del sargento mayor Pablo Hernández. Santa Fe, 20 de octubre de 1703 .

xxiv

A.H.U. Documentos catalogados Río 16.840. Publicado por Castro e Almeida (1913 - 1921).

$\mathrm{xxv}$

Especialmente llama la atención que 5 de las 10 u 11 de cada toldo serían guerreros aunque eran considerados tales después de los 12 o 13 años.

xxvi

Alvear, Diego de. Diario de la segunda subdivisión de límites española. Recuperado en agosto de 2019 de https://www.biblioteca.org.ar/libros/130485.pdf [El pdf referido indica páginas 344 y 345. No señala si se ha hecho a partir del original ni, en este caso, su ubicación. Posiblemente se realizó a partir de: Alvear, Diego de (1900). En adelante así se considera.

xxvii

Museo Histórico Nacional (Uruguay). Colección de Manuscritos, Tomo 1010. Tercer cuaderno del diario de operaciones de Jorge Pacheco.

xxviii

A.G.N. Colección Pivel Devoto Tomo I, Caja 3, Carpeta 10. Diario de Juan Bentura Isfrán con lo acontecido a su expedición desde 10 de marzo hasta 10 de junio de 1800.

xxix 
A.G.N.A., Tribunales, legajo 66, expediente 38. Adjunto a oficio de Francisco Bruno de Zabala al virrey Arredondo. Candelaria, 25 de abril de 1794.

$\mathrm{xxx}$

La cohabitación en un espacio reducido con "tres mujeres suyas" parece lejano a nuestro presente, especialmente si está referido a lo que generalmente se denomina "Occidente". No obstante en el seno de la sociedad colonial en aquel medio "la falta de escrúpulos como persistencia de costumbres salvajes e indecorosas como la de dormir padres e hijos en un mismo dormitorio". Efectivamente, el retrato que algunos casos judiciales nos dejan cuando se hace referencia al incesto en presencia de los restantes miembros de la familia es francamente impactante" (Mayo 2004: 170 - 171).

xxxi

"Testimonio de sumaria seguida contra los presos Esteban Aripuy, Ambrosio Yarí, Manuel Antonio y Pedro de Mora, Pedro Antonio Rivero, procedentes de los dominios de Portugal, y aprendidos por el teniente don José Artigas en la campaña" 7 de junio de 1804. (Archivo Artigas 1951: II, 295 - 296).

xxxii

Cabe preguntarse si los "cloya" que aparecen como parcialidad entre las guenoa minuanas son parciales del cacique Cloyan.

xxxiii

"Testimonio de sumaria seguida contra los presos Esteban Aripuy, Ambrosio Yarí, Manuel Antonio y Pedro de Mora, Pedro Antonio Rivero, procedentes de los dominios de Portugal, y aprendidos por el teniente don José Artigas en la campaña" 7 de junio de 1804. (Archivo Artigas 1951: II, 295 -296).

xxxiv

Arquivo Histórico Ultramarino. Lisboa. Río de Janeiro, doc. № 3580.

$\operatorname{xxxv}$

No hay como aproximarse a las pautas de desplazamiento de los guenoa minuanos en el estado actual del conocimiento. No obstante es interesante señalar que la autoridad de los caciques de caciques alcanzaba un espacio considerablemente mayor que la actual República Oriental del Uruguay. Asimismo que algunos caciques fueron a Buenos Aires. En el año 1717, el gobernador Zabala ordenó el pago a favor del teniente Francisco Romero de \$ 17 y 3 reales "que por convenir al real servicio... se emplearon en dar a los caciques minuanes (que vinieron de la otra banda). A.G.I., Contaduría, 1932. Orden de pago del gobernador Zabala y recibo de Romero, de 4 de diciembre de 1717 .

xxxvi

A.G.I., Contaduría 1931. Instrucción del gobernador Velazco y Tejada al capitán Rámila. Buenos Aires, 4 de marzo de 1710. Inserta en pleito del capitán Tomás de Quiñones del año 1713.

xxxvii

A.G.I., Charcas, 264. Expediente de 1716 sobre intento de contrabando de García Inclán.

xxxviii

Arquivo Histórico Ultramarino. Lisboa. Río de Janeiro, doc. № 3580.

xxxix

Arquivo Histórico Ultramarino. Lisboa. Río de Janeiro, doc. $\mathrm{N}^{\circ} 3580$.

$\mathrm{xl}$

Arquivo Histórico Ultramarino. Lisboa. Río de Janeiro, doc. № 3580.

xli

A.G.I., Charcas, 264. Expediente de 1716 sobre intento de contrabando de García Inclán.

xlii

En numerosas ocasiones los "infieles" de la región perdieron la mayoría de sus mujeres y niños (Bracco 2013). Un ejemplo de especial dureza es el de los 80 guerreros bohanes a quienes, tras la guerra de 1701 - 1702, les quedaban 18 mujeres A.G.N.A. XI-41-1-3. exp. 4. Declaración del sargento mayor Pablo Hernández. Santa Fe, 20 de octubre de 1703 (Bracco 2004: 251)

xliii

Saldanha, José de. Diario resumido e histórico (1786 - 1787) Noticia sobre los minuanos. Tomado de Acosta y Lara (1998: 248 -251).

xliv

Excepcionalmente conocemos la peripecia de Francisco Borja, guenoa minuan que había aceptado el cristianismo. Fue atacado a instigación de su mujer e hijos por por un "hechicero" en 1732, cuando visitaba a los suyos acompañando al padre Jiménez. Resultas del ataquel murió tres meses más tarde. (Carta Anua de 1730 1734 en Manuscritos da Coleçâo de Angelis 1955: 167, 168 y 170)".

$\mathrm{xlv}$ 
Debió haber una relevante "periferia" en los pueblos de misiones, en los que la poliginia debe haberse mantenido quizás durante prolongado lapso. Tal como destacó Wilde (2009: 25 - 31) la gran mayoría de lo que sabemos de esos pueblos procede de aquello que los jesuitas estuvieron interesados en divulgar.

xlvi

Por ejemplo en los padrones de la década de 1750 correspondientes a la reducción charrúa de Cayastá (Bracco 2016). Hacia mediados de siglo XVIII Leonarda, pampa "infiel”, viuda de Calelián, que "proseguía con sus altiveces de cacica" mostró liderazgo sobre otras que compartían su suerte de "desnaturalizada". A.G.N.A. IX-23-3-4. Zabala al gobernador de Buenos Aires. Víboras, 15 de noviembre de 1750.

xlvii

Consulta al Consejo y resolución regia de 3 de setiembre y 5 de noviembre de 1718, en Lisboa. Arquivo Histórico Ultramarino. Río de Janeiro, doc. Nº 3580.

xlviii

No parece referirse a Petrona que, como se ha visto, fue intérprete en la paz del año 1762. Cabe conjeturar que debía tratarse de alguien que no había aceptado el cristianismo porque de lo contrario difícilmente se le permitiera reunirse con un "infiel”. Acta del Cabildo de Montevideo. 29 de marzo de 1766. En Revista del Archivo General Administrativo III, 288 - 293.

xlix

Saldanha, José de. Diario resumido e histórico (1786 - 1787) Noticia sobre los minuanos. Tomado de Acosta y Lara (1998: 248 -251).

1

A.G.I., Charcas, 226. Los Oficiales Reales al Rey. Buenos Aires, 10 de setiembre de 1721.

li A.G.I., Charcas, 221. La ciudad de Buenos Aires al Rey. Buenos Aires, 12 de setiembre de 1721.

lii Jornal do Comercio. Edición impresa de 17 de mayo de 2019. Porto Alegre Disponible en https://www.jornaldocomercio.com/_conteudo/cultura/2019/05/683717-expedicao-rumo-ao-passado.html liii

Una síntesis de la investigación fue divulgada por la prensa. Jornal do Comercio (Porto Alegre, Brasil) segunda-feira, 07 de outubro de 2019. Recuperado en agosto de 2019 de https://www.jornaldocomercio.com/_conteudo/cultura/2019/05/683717-expedicao-rumo-ao-passado.html 